University of Nebraska - Lincoln

DigitalCommons@University of Nebraska - Lincoln

\title{
Factors Influencing Receipt of Outpatient Rehabilitation Services Among Veterans Following Lower Extremity Amputation
}

Jianxun Zhou

Samuel S. Stratton Veterans Affairs Medical Center Albany

Barbara E. Bates

Samuel S. Stratton Veterans Affairs Medical Center Albany

Jibby E. Kurichi

Center for Clinical Epidemiology and Biostatistics

Pui L. Kwong

Center for Clinical Epidemiology and Biostatistics

Dawei Xie

Center for Clinical Epidemiology and Biostatistics

See next page for additional authors

Follow this and additional works at: https://digitalcommons.unl.edu/publichealthresources

Part of the Public Health Commons

Zhou, Jianxun; Bates, Barbara E.; Kurichi, Jibby E.; Kwong, Pui L.; Xie, Dawei; and Stineman, Margaret G., "Factors Influencing Receipt of Outpatient Rehabilitation Services Among Veterans Following Lower Extremity Amputation" (2011). Public Health Resources. 204.

https://digitalcommons.unl.edu/publichealthresources/204

This Article is brought to you for free and open access by the Public Health Resources at DigitalCommons@University of Nebraska - Lincoln. It has been accepted for inclusion in Public Health Resources by an authorized administrator of DigitalCommons@University of Nebraska - Lincoln. 


\section{Authors}

Jianxun Zhou, Barbara E. Bates, Jibby E. Kurichi, Pui L. Kwong, Dawei Xie, and Margaret G. Stineman 


\title{
Factors Influencing Receipt of Outpatient Rehabilitation Services Among Veterans Following Lower Extremity Amputation
}

\author{
Jianxun Zhou, MD, PhD, Barbara E. Bates, MD, Jibby E. Kurichi, MPH, Pui L. Kwong, MPH, \\ Dawei Xie, PhD, Margaret G. Stineman, MD
}

ABSTRACT. Zhou J, Bates BE, Kurichi JE, Kwong PL, Xie D, Stineman MG. Factors influencing receipt of outpatient rehabilitation services among veterans following lower extremity amputation. Arch Phys Med Rehabil 2011;92:1455-61.

Objective: To determine patient-, treatment-, and facilitylevel characteristics associated with receiving outpatient rehabilitation services after lower extremity amputation within the Veterans Affairs (VA) system.

Design: Observational study.

Setting: All Veterans Affairs Medical Centers (VAMCs).

Participants: Veterans $(\mathrm{N}=4165)$ with lower extremity amputation discharged from VAMCs between October 1, 2002, and September 20, 2004.

Interventions: Not applicable.

Main Outcome Measures: Receipt of outpatient rehabilitation services up to 1 year postdischarge. A Cox proportional hazards model was used to determine the adjusted hazard ratio and $95 \%$ confidence interval of veterans to receive outpatient services.

Results: Sixty-five percent of veterans with lower extremity amputation received outpatient services. Older veterans, patients admitted for surgical amputation from extended care rather than transferred from another hospital, and those with transfemoral and/or bilateral rather than unilateral transtibial amputations were less likely to receive outpatient services. Those with serious comorbidities and those who had procedures for acute central nervous system disorders, active cardiac pathology, serious nutritional compromise, and severe renal disease during the surgical hospitalization less often initiated outpatient care. Patients who received inpatient consultative rehabilitation compared with inpatient specialized rehabilitation, and who were treated in the Northeast compared with the Southeast less often initiated outpatient care. Finally, those discharged to home or other locations rather than extended care had an initial increased likelihood of receiving outpatient service, but by 180 days postdischarge those discharged to extended care were more likely to initiate outpatient services.

Conclusions: Both clinical characteristics and types of rehabilitation services received appear to influence the receipt of outpatient rehabilitation services. Geographic location also af-

From Physical Medicine and Rehabilitation Service, the Samuel S. Stratton Veterans Affairs Medical Center Albany, Albany, NY (Zhou, Bates); and Department of Physical Medicine and Rehabilitation (Stineman) and Department of Biostatistics and Epidemiology, Center for Clinical Epidemiology and Biostatistics (Kurichi, Kwong, Xie, Stineman), School of Medicine University of Pennsylvania, Philadelphia, PA.

No commercial party having a direct financial interest in the results of the research supporting this article has or will confer a benefit on the authors or on any organization with which the authors are associated.

Correspondence to Jianxun Zhou, MD, PhD, Samuel S. Stratton VAMC Albany, 113 Holland Ave, Albany, NY 12208, e-mail: zhouj@mail.amc.edu. Reprints are not available from the authors.

0003-9993/11/9209-01020\$36.00/0

doi:10.1016/j.apmr.2011.03.029 fected the receipt of outpatient rehabilitation, suggesting that care patterns are not standardized across the nation.

Key Words: Amputation; Rehabilitation; Veterans.

(C) 2011 by the American Congress of Rehabilitation Medicine

$\mathbf{V}^{-1}$ ETERANS WHO HAVE undergone lower extremity amputation may experience long-term challenges after discharge from their acute hospitalization. For patients with the potential to walk with a prosthetic limb, continuity of rehabilitation after discharge is critical. For patients who are not appropriate for prosthetic fitting, mobility needs including wheelchair and transfer skills may be best managed in an outpatient rehabilitation setting. Patients may also have pain management needs for phantom pain and stump pain, and require follow-up of the quality and functionality of the residual extremity. ${ }^{1}$ Psychosocial adjustment to a lower extremity amputation can last for up to 2 years, ${ }^{2}$ requiring ongoing outpatient services.

Rehabilitation services after lower extremity amputation provide the opportunity for rehabilitation specialists to assess patients' functional goals and adjust interventions to achieve maximum independence and function. Cumulative evidence supports the notion that inpatient rehabilitation leads to better outcomes, including reduced mortality, fewer subsequent amputations, greater medical stability, greater likelihood of home discharge, prosthetic fitting, and improved physical functioning. ${ }^{3-6}$

Given their long-term challenges, it is reasonable to assume that most patients could benefit from outpatient rehabilitation after hospitalization for an amputation. However, many patients with severe lower extremity trauma requiring amputation received no physical therapy services despite the perceived need. ${ }^{7}$ Castillo et $\mathrm{al}^{8}$ found that, compared with those who received no physical therapy services, there is a beneficial effect of physical therapy for patients with severe lower ex-

List of Abbreviations

\begin{tabular}{|c|c|}
\hline BIRLS & $\begin{array}{l}\text { Beneficiary Identification Record Locator } \\
\text { System }\end{array}$ \\
\hline $\mathrm{Cl}$ & confidence interval \\
\hline FSOD & Functional Status and Outcomes Database \\
\hline$H R$ & hazard ratio \\
\hline ICD-9-CM & $\begin{array}{l}\text { International Classification of Diseases, Ninth } \\
\quad \text { Revision, Clinical Modification }\end{array}$ \\
\hline PTF & Patient Treatment Files \\
\hline SRU & specialized rehabilitation unit \\
\hline VA & Veterans Affairs \\
\hline VAMC & Veterans Affairs Medical Center \\
\hline VHA & Veterans Health Administration \\
\hline
\end{tabular}


tremity trauma requiring amputation or reconstruction. Little is known about participation in outpatient rehabilitation services after lower extremity amputation for nontraumatic etiologies. In this study, we examined patient-, treatment-, and facilitylevel characteristics associated with participation in outpatient rehabilitation after lower extremity amputation within the Veterans Affairs (VA) health care system. Identification of these characteristics may help clinicians better understand the barriers to receiving outpatient rehabilitation and take appropriate action when needed for patients with lower extremity amputation.

\section{METHODS}

This observational study was approved by the institutional review boards at the Samuel S. Stratton Veterans Affairs Medical Center (VAMC) in Albany, New York, the University of Pennsylvania in Philadelphia, Pennsylvania, and North Florida/ South Georgia Veterans Health System in Gainesville, Florida.

\section{Description of Databases}

Data were obtained from 8 Veterans Health Administration (VHA) administrative databases used to track the health status and health care utilization of veterans. The databases included 4 inpatient datasets referred to as the Patient Treatment Files (PTF) (main, procedure, bed section, and surgery), ${ }^{9} 2$ outpatient care files (visit and event), ${ }^{10}$ the Beneficiary Identification Record Locator System (BIRLS) death file, ${ }^{11}$ and the Functional Status and Outcomes Database (FSOD). ${ }^{12}$ Description of the PTF, BIRLS, and FSOD databases and our data extraction methods have been described previously. ${ }^{13-16}$ The outpatient files track any outpatient services received along with diagnoses coded during those visits and visit dates. To ensure that all visits were captured, we created our "evidence of outpatient rehabilitation" group by combining information from 2 variables: "clinic stop," which describes the types of services received, and "provider type," which records who saw the patient.

\section{Study Population}

Patients were included from VAMCs with acute hospital discharge dates between October 1, 2002, and September 30, 2004, for a transtibial or transfemoral amputation identified through the after surgical International Classification of Diseases, Ninth Revision, Clinical Modification (ICD-9-CM) procedure codes: $84.10,84.13$ through 84.19 , and $84.91 .^{17}$ Cases were excluded if the amputation involved toes only or if there was a record of a previous lower extremity amputation within the 12 months preceding the hospitalization, since the objective was to study only new amputations. The hospitalization (admission to discharge) at the time of the new amputation represented the "index surgical stay" or acute hospital stay. We combined records from the PTF bed section files with admission dates within 1 day of the patient's main hospitalization discharge date to capture the entire acute amputation hospitalization stay. Data include information up to the 1-year postsurgical date.

We started with a total of 4727 subjects. Because the focus of the study was to determine which characteristics predicted the receipt of outpatient rehabilitation services after the patients were discharged from the hospital, the following groups of patients were excluded: 364 patients who died during the index surgical stay, 17 patients whose index surgical stay extended more than 365 days after the surgical amputation, and 131 who were discharged to another hospital. We also excluded 50 more patients because they were missing at least 1 of the predictors.
In detail, there were 49 patients with a V57 code indicating that they received inpatient rehabilitation, but had no evidence of an FSOD record to designate which type of rehabilitation was received during the surgical hospitalization, and 1 patient whose living location before hospitalization was missing. Thus, 4165 veterans with a lower extremity amputation were included in the analyses.

\section{Description of Inpatient and Outpatient Rehabilitation Services}

The type of inpatient rehabilitation was included to determine whether having some form of rehabilitation acutely after surgery made continued outpatient care more or less likely. Details of inpatient rehabilitation services have been described previously. ${ }^{5}$ Briefly, in the VHA, inpatient rehabilitation is classified into consultation rehabilitation and specialized rehabilitation. In consultation rehabilitation, patients may have 1 to several therapy sessions while hospitalized, and functional restoration is not typically the primary therapeutic focus. Inpatient rehabilitation on a specialized rehabilitation unit (SRU) occurs on designated units, in which restorative therapy occurs daily, and rehabilitation is the primary therapeutic focus. In the VHA, subacute and acute SRU beds within hospitals are considered to be similar, and in this study both were categorized as an SRU because of the low frequency of veterans who receive SRU and subacute rehabilitation services after their amputations.

Outpatient rehabilitation occurs after discharge from the index surgical stay. There are multiple types of outpatient rehabilitation services that patients can receive, which are described in detail in the outcome measure section.

\section{Patient-, Treatment-, and Facility-Level Characteristics}

Table 1 shows details of these characteristics. Patients with both a unilateral transtibial and a unilateral transfemoral amputation were categorized as bilateral transfemoral amputations because of the low prevalence of bilateral transfemoral amputations, and because patient-level characteristics were more closely related to transfemoral amputations (ie, functional prognosis declines sharply once the knee is lost). ${ }^{18}$

Etiologies and comorbidities were identified by using ICD9-CM diagnosis codes from outpatient care files 3 months before the hospital admission and from the main and bed section PTF files up to the surgical date. Congenital deformity and lower extremity cancer were not sufficiently prevalent to be included in the analyses. We used the 2003 version of the Elixhauser comorbidity measure (Comorbidity Software 3.1), which includes 31 conditions and distinguishes hypertension with and without complications, in this study. ${ }^{19}$ No cases had the ICD-9-CM code for obesity, and thus obesity was not included. Diabetes mellitus and peripheral vascular disease were not included as comorbidities because they were categorized as amputation etiologies. Admission to an intensive care unit was intended to indicate that the patient had a high level of medical acuity at some point during the surgical hospitalization. Discharge locations include home; extended care including nursing home, domiciliary, and long-term care; and others (see table 1).

\section{Outcome Measure}

The outcome of this study was time to the first outpatient rehabilitation service from the discharge date of the index hospitalization. Evidence of outpatient rehabilitation was obtained by combining information from clinic stops and type of 
Table 1: Summary of Patient-, Treatment-, and Facility-Level Characteristics

\begin{tabular}{|c|c|}
\hline Variables & Descriptions \\
\hline Patient-level & $\begin{array}{l}\text { 1. General: Age, gender, marital status, living location (extended care, }{ }^{*} \text { home, or hospital). } \\
\text { 2. Level of amputation: Unilateral transtibial, unilateral transfemoral, bilateral transtibial, and bilateral } \\
\text { transfemoral. } \\
\text { 3. Contributing amputation etiologies: Chronic osteomyelitis, device infection, diabetes mellitus type } \\
\text { 1, diabetes mellitus type 2, local significant infection, peripheral vascular disease, previous } \\
\text { amputation complication, skin breakdown, systemic sepsis, and trauma. } \\
\text { 4. Elixhauser comorbidities, which include } 31 \text { conditions: congestive heart failure, arrhythmias, } \\
\text { valvular disease, pulmonary circulation disease, peripheral vascular disease, hypertension, } \\
\text { hypertension with complication, paralysis, other neurologic disorders, chronic pulmonary disease, } \\
\text { diabetes mellitus, diabetes mellitus with complication, hypothyroidism, renal failure, liver disease, } \\
\text { peptic ulcer disease, acquired immune deficiency syndrome, lymphoma, metastatic cancer, solid } \\
\text { tumor without metastases, rheumatoid arthritis, coagulopathy, obesity, weight loss, fluid and } \\
\text { electrolyte disorders, chronic blood loss anemia, deficiency anemia, alcohol abuse, drug abuse, } \\
\text { psychoses, and depression. } \\
\text { Note: Diabetes mellitus and peripheral vascular disease were excluded to avoid double counting, } \\
\text { since they were already in the etiologies. }\end{array}$ \\
\hline Treatment-level & $\begin{array}{l}\text { 1. Treatments/procedures for active pulmonary, central nervous system, cardiac, or severe renal } \\
\text { pathology, nutritional compromise, ongoing wound problems, and mental status issues or } \\
\text { substance abuse. } \\
\text { 2. Admission to an intensive care unit. } \\
\text { 3. Average number of bed sections. } \\
\text { 4. Average days from hospital admission to surgery. } \\
\text { 5. Average days from surgical date to discharge date. } \\
\text { 6. Type of inpatient rehabilitation (no inpatient rehabilitation, consultation rehabilitation, or specialized } \\
\text { rehabilitation). } \\
\text { 7. Discharge location: extended care* }{ }^{*} \text { home, }{\text { or } \text { other. }^{\dagger}}^{+}\end{array}$ \\
\hline Facility-level & $\begin{array}{l}\text { 1. Geographic region: Northeast, Southeast, Midwest, South Central, or Pacific Mountain. } \\
\text { 2. Hospital bed size: } \leq 126,127-244,245-362 \text {, or }>362 \text {. }\end{array}$ \\
\hline
\end{tabular}

NOTE. See text for explanations.

*Extended care: nursing home, domiciliary, long-term.

${ }^{\dagger}$ Other: leave against medical advice, or other placements including hospital-based home care, spinal cord injury program, home care unit program, Medicare home health, and other home health.

provider codes in the outpatient care files, each of which includes a date of service. This outcome was structured so that it captured both (1) whether the individual had any or no outpatient rehabilitation, and (2) the time between discharge from the surgical hospitalization and the first outpatient visit. The clinician authors (J.Z., B.B., M.S.) reviewed and combined both outpatient clinic stops codes and types of providers. These codes, obtained from the outpatient record, were used to categorize the nature of the first outpatient rehabilitation contact as follows: physical medicine, recreation therapy, physical therapy, occupational therapy, kinesiotherapy, and postamputation clinic. ${ }^{10}$ Further details about the codes used for each category are in table 2.

\section{Statistical Analyses}

Baseline patient-, treatment-, and facility-level characteristics were compared between patients who did and did not receive outpatient rehabilitation services. These comparisons

Table 2: Types of First Outpatient Rehabilitation Services Received After Acute Surgical Hospitalization Discharge

\begin{tabular}{|c|c|c|c|c|c|}
\hline \multirow[b]{2}{*}{ Service Classification } & \multirow[b]{2}{*}{ Clinic Stop/Providers Type } & \multirow[b]{2}{*}{ n (\%) } & \multicolumn{3}{|c|}{$\begin{array}{c}\text { Time Between Discharge Date and First } \\
\text { Outpatient Visit (d) }\end{array}$} \\
\hline & & & Mean $\pm S D$ & Median & Range (d) \\
\hline Physical medicine & $\begin{array}{l}\text { Physical medicine and rehabilitation service/ } \\
\text { Physical medicine and rehabilitation }\end{array}$ & $205(7.6)$ & $50.7 \pm 57.5$ & 33 & 334 \\
\hline Recreation therapy & $\begin{array}{l}\text { Recreation therapy service/Recreation } \\
\text { therapist }\end{array}$ & $25(0.9)$ & $69.7 \pm 58.8$ & 65 & 178 \\
\hline Physical therapy & Physical therapy/Physical therapist & $350(13.0)$ & $37.0 \pm 53.4$ & 15 & 293 \\
\hline Occupational therapy & Occupational therapy/Occupational therapist & $187(6.9)$ & $44.2 \pm 60.5$ & 19 & 289 \\
\hline Kinesiotherapy & Kinesiotherapy & $144(5.3)$ & $41.0 \pm 60.5$ & 17 & 343 \\
\hline Postamputation clinic & $\begin{array}{l}\text { Amputation follow-up clinic; Prosthetic, } \\
\text { orthotics, evaluation, fitting, and/or } \\
\text { measuring; Amputation clinic;Prosthetic } \\
\text { supply ordering services }\end{array}$ & $1786(66.2)$ & $35.8 \pm 52.3$ & 13 & 330 \\
\hline Overall & & $2697(100 \%)$ & $38.3 \pm 54.2$ & 15 & 343 \\
\hline
\end{tabular}


Table 3: Baseline Patient-, Treatment-, and Facility-Level Characteristics That Are Significantly Associated With Outpatient Rehabilitation Service Use

\begin{tabular}{|c|c|c|c|}
\hline & $\begin{array}{c}\text { Do Not Have } \\
\text { Outpatient } \\
\text { ( } n=1468)\end{array}$ & $\begin{array}{c}\text { Had } \\
\text { Outpatient } \\
(\mathrm{n}=2697)\end{array}$ & $P$ \\
\hline \multicolumn{4}{|l|}{ Demographic variables } \\
\hline Average age (y) & $69.8 \pm 10.7$ & $64.8 \pm 11.1$ & $<.0001$ \\
\hline Marital status & & & .0002 \\
\hline Not married & $863(37.7)$ & $1426(62.3)$ & \\
\hline Married & $605(32.3)$ & $1271(67.7)$ & \\
\hline \multicolumn{4}{|l|}{ Living location before } \\
\hline hospitalization & & & $<.0001$ \\
\hline Extended care & $349(74.4)$ & $120(25.6)$ & \\
\hline Hospital & $30(33.0)$ & $61(67.0)$ & \\
\hline Home & $1089(30.2)$ & $2516(69.8)$ & \\
\hline Level of amputation & & & $<.0001$ \\
\hline Unilateral transtibial & $456(26.3)$ & $1276(73.7)$ & \\
\hline Unilateral transfemoral & $359(35.6)$ & $649(64.4)$ & \\
\hline Bilateral transtibial & $39(43.8)$ & $50(56.2)$ & \\
\hline Bilateral transfemoral & $614(46.0)$ & $722(54.0)$ & \\
\hline \multicolumn{4}{|l|}{ Amputation etiology } \\
\hline \multicolumn{4}{|l|}{ Device infection } \\
\hline No & $1331(36.1)$ & $2360(63.9)$ & .002 \\
\hline Yes & $137(28.9)$ & $337(71.1)$ & \\
\hline \multicolumn{4}{|l|}{ Diabetes mellitus type 1} \\
\hline No & $1263(36.0)$ & $2249(64.0)$ & .02 \\
\hline Yes & $205(31.4)$ & $448(68.6)$ & \\
\hline \multicolumn{4}{|l|}{ Local significant infection } \\
\hline No & $292(30.0)$ & $680(70.0)$ & .0001 \\
\hline Yes & $1176(36.8)$ & $2017(63.2)$ & \\
\hline \multicolumn{4}{|c|}{ Peripheral vascular disease } \\
\hline No & $158(28.6)$ & $394(71.4)$ & .0005 \\
\hline Yes & $1310(36.3)$ & $2303(63.7)$ & \\
\hline \multicolumn{4}{|l|}{ Systemic sepsis } \\
\hline No & $1307(34.6)$ & $2467(65.4)$ & .01 \\
\hline Yes & $161(41.2)$ & $230(58.8)$ & \\
\hline \multicolumn{4}{|l|}{ Trauma } \\
\hline No & $1280(35.9)$ & $2282(64.1)$ & .02 \\
\hline Yes & $188(31.2)$ & 415 (68.8) & \\
\hline \multicolumn{4}{|l|}{ Elixhauser comorbidities } \\
\hline \multicolumn{4}{|l|}{ Arrhythmias } \\
\hline No & $1181(34.0)$ & $2297(66.0)$ & $<.0001$ \\
\hline Yes & $287(41.8)$ & $400(58.2)$ & \\
\hline \multicolumn{4}{|c|}{ Chronic pulmonary disease } \\
\hline No & $1137(33.9)$ & $2213(66.1)$ & .0003 \\
\hline Yes & $331(40.6)$ & $484(59.4)$ & \\
\hline \multicolumn{4}{|l|}{ Congestive heart failure } \\
\hline No & $1070(33.2)$ & $2150(66.8)$ & $<.0001$ \\
\hline Yes & $398(42.1)$ & $547(57.9)$ & \\
\hline \multicolumn{4}{|l|}{ Deficiency anemias } \\
\hline No & $1082(33.6)$ & $2134(66.4)$ & $<.0001$ \\
\hline Yes & $386(40.7)$ & $563(59.3)$ & \\
\hline \multicolumn{4}{|l|}{ Drug abuse } \\
\hline No & $1448(35.6)$ & $2614(64.4)$ & .0007 \\
\hline Yes & $20(19.4)$ & $83(80.6)$ & \\
\hline \multicolumn{4}{|c|}{ Fluid and electrolyte disorders } \\
\hline No & $1122(34.0)$ & $2175(66.0)$ & .001 \\
\hline Yes & $346(39.9)$ & $522(60.1)$ & \\
\hline \multicolumn{4}{|l|}{ Hypertension } \\
\hline No & $583(37.7)$ & $964(62.3)$ & .01 \\
\hline Yes & $885(33.8)$ & $1733(66.2)$ & \\
\hline Other neurologic disord & & & \\
\hline No & $1410(34.8)$ & $2647(65.2)$ & $<.0001$ \\
\hline Yes & $58(53.7)$ & $50(46.3)$ & \\
\hline
\end{tabular}

Table 3: Baseline Patient-, Treatment-, and Facility-Leve Characteristics That Are Significantly Associated With Outpatient Rehabilitation Service Use (Cont'd)

\begin{tabular}{|c|c|c|c|}
\hline & $\begin{array}{c}\text { Do Not Have } \\
\text { Outpatient } \\
\text { (n=1468) }\end{array}$ & $\begin{array}{c}\text { Had } \\
\text { Outpatient } \\
(n=2697)\end{array}$ & $P$ \\
\hline \multicolumn{4}{|l|}{ Paralysis } \\
\hline No & $1428(35.7)$ & $2575(64.3)$ & .004 \\
\hline Yes & $40(24.7)$ & $122(75.3)$ & \\
\hline \multicolumn{4}{|l|}{ Psychoses } \\
\hline No & $1339(34.6)$ & $2529(65.4)$ & .002 \\
\hline Yes & $129(43.4)$ & $168(56.6)$ & \\
\hline \multicolumn{4}{|l|}{ Renal failure } \\
\hline No & $1167(34.1)$ & $2253(65.9)$ & .001 \\
\hline Yes & $301(40.4)$ & $444(59.6)$ & \\
\hline \multicolumn{4}{|l|}{ Valvular disease } \\
\hline No & $1380(34.7)$ & $2598(65.3)$ & .0005 \\
\hline Yes & $88(47.1)$ & $99(52.9)$ & \\
\hline \multicolumn{4}{|l|}{ Weight loss } \\
\hline No & $1373(34.7)$ & $2581(65.3)$ & .002 \\
\hline Yes & $95(45.0)$ & $116(55.0)$ & \\
\hline \multicolumn{4}{|l|}{ Treatment variables } \\
\hline \multicolumn{4}{|l|}{ Procedures } \\
\hline \multicolumn{4}{|l|}{ Active pulmonary pathology } \\
\hline No & $1450(35.1)$ & $2683(64.9)$ & .01 \\
\hline Yes & $18(56.2)$ & $14(43.8)$ & \\
\hline \multicolumn{4}{|l|}{ Acute central nervous disorder } \\
\hline No & $1338(34.6)$ & $2533(65.4)$ & .0008 \\
\hline Yes & $130(44.2)$ & $164(55.8)$ & \\
\hline \multicolumn{4}{|l|}{$\begin{array}{l}\text { Ongoing active cardiac } \\
\text { pathology }\end{array}$} \\
\hline No & $1284(34.6)$ & $2426(65.4)$ & .01 \\
\hline Yes & $184(40.4)$ & $271(59.6)$ & \\
\hline \multicolumn{4}{|c|}{ Serious nutritional compromise } \\
\hline No & $1389(34.4)$ & $2643(65.6)$ & $<.0001$ \\
\hline Yes & $79(59.4)$ & $54(40.6)$ & \\
\hline \multicolumn{4}{|l|}{ Severe renal disease } \\
\hline No & 1309 (34.3) & $2510(65.7)$ & $<.0001$ \\
\hline Yes & $159(46.0)$ & $187(54.0)$ & \\
\hline \multicolumn{4}{|l|}{ ICU admission } \\
\hline No & $864(32.4)$ & $1803(67.6)$ & $<.0001$ \\
\hline Yes & $604(40.3)$ & $894(59.7)$ & \\
\hline \multicolumn{4}{|l|}{ Average number of bed } \\
\hline sections & $2.4 \pm 1.8$ & $2.3 \pm 1.7$ & .04 \\
\hline \multicolumn{4}{|l|}{ Average days from hospital } \\
\hline admission to surgery & $8.9 \pm 16.3$ & $7.8 \pm 11.5$ & .02 \\
\hline \multicolumn{4}{|l|}{ Acute postoperative type of } \\
\hline rehabilitation & & & $<.0001$ \\
\hline \multicolumn{4}{|l|}{ No evidence of inpatient } \\
\hline rehabilitation & $543(45.6)$ & $649(54.4)$ & \\
\hline Consultative & 806 (33.9) & $1571(66.1)$ & \\
\hline Specialized & $119(20.0)$ & $477(80.0)$ & \\
\hline Discharge location & & & $<.0001$ \\
\hline Home & $609(24.4)$ & $1892(75.3)$ & \\
\hline Extended care & $852(52.1)$ & $782(47.9)$ & \\
\hline Other & $7(23.3)$ & $23(76.7)$ & \\
\hline Hospital characteristics & & & $<.0001$ \\
\hline \multicolumn{4}{|l|}{ Regions } \\
\hline Northeast & $270(47.4)$ & $300(52.6)$ & \\
\hline Southeast & $458(36.3)$ & 804 (63.7) & \\
\hline Midwest & $219(28.1)$ & $561(71.9)$ & \\
\hline South Central & $292(32.0)$ & $622(68.0)$ & \\
\hline Mountain Pacific & $229(35.8)$ & $410(64.2)$ & \\
\hline
\end{tabular}

NOTE. Values are mean $\pm \mathrm{SD}, \mathrm{n}(\%)$, or as otherwise indicated. For categorical variables, $P$ values correspond to the significance of the association between the outpatient rehabilitation service use and the overall variable. Statistical significance was set at $P<.05$. Abbreviation: ICU, intensive care unit. 
were conducted through chi-square tests for categorical variables or Student $t$ tests for continuous variables.

A time-to-event analysis (ie, Cox proportional hazards model) was used to determine the hazard ratio (HR) and $95 \%$ confidence interval (CI) of veterans to receive outpatient rehabilitation services. Veterans who died after discharge without evidence of any outpatient rehabilitation were censored at the death date. There were only 26 patients falling into this category, so we did not consider an analysis to resolve the competing risk issue. Each patient-, treatment-, and facility-level variable was entered alone to predict time to receipt of outpatient rehabilitation services. If the $P$ value was less than .05, then the variable was included in the multivariate model. In the multivariate model, we also included clinically important variables such as age, marital status, amputation level, living location before hospitalization, and discharge location. Backward selection was then used to remove variables 1 at a time to construct the final main effects model in which all $P$ values were less than .05.

The proportional hazards assumption for the Cox regression model was tested to determine whether the HRs remained constant over time. To do this, the interaction between each predictor in the final main effects model and time to receipt of outpatient rehabilitation services was added to the final main effects model. We added all interactions with a $P$ value of less than .05 in the previous step before a final backward selection procedure was conducted to obtain the final model with main effect and interactions. If a variable violated the proportional hazards assumption, it means that the HR for this variable is changing over time, and we chose to show the HRs at some discrete time points during the follow-up period. Specifically, HRs and 95\% CIs at 0,90, 180, 270, and 365 days after discharge from the index surgical stay were calculated. The constant HRs and 95\% CIs for the predictors not violating the hazards assumption were reported. All models took into account the correlation among patients from the same facility. This was necessary because patients from the same facility might have correlated outcomes even after adjusting for all the covariates in our dataset. For example, the clinicians from the same facility might have similar approaches to outpatient service use, causing correlations of outcomes within a center after removing the effects of all observed covariates. Accounting for the correlation allows us to obtain the correct variance estimate.

PROC TPHREG in SAS version $9.1^{\mathrm{b}}$ was used for all time-to-event analyses. $P$ values were 2 -sided, with statistical significance at $P<.05$ in the final model. Our tables included only the variables that were statistically significantly associated with outpatient use.

\section{RESULTS}

There were a total of 2697 veterans $(64.75 \%)$ with lower extremity amputation who received outpatient rehabilitation services based on clinic stop and provider type codes, while $1468(35.25 \%)$ did not. Among those who received outpatient rehabilitation services, the average time \pm SD between discharge from the surgical hospitalization and first visit was $38.3 \pm 54.2$ days (see table 2 ). Outpatient services were most commonly initiated by a visit to an amputee clinic. This was the pattern for $66.2 \%$ of all veteran amputees with any outpatient services after discharge.

Table 3 compares baseline unadjusted characteristics of patients who did and did not receive outpatient rehabilitation services. Only statistically significant associations are shown. After adjusting for patient-, treatment-, and facility-level characteristics, some of these associations are no longer statistically
Table 4: Cox Proportional Hazard Analysis Demonstrating Characteristics Still Associated With the Receipt of Outpatient Services After Statistical Adjustment

\begin{tabular}{lccc}
\hline \multicolumn{1}{c}{ Characteristics } & HR & $95 \% \mathrm{Cl}$ & $P$ \\
\hline $\begin{array}{l}\text { Demographic contents } \\
\text { Every 10-year increase in age }\end{array}$ & 0.83 & $0.80-0.86$ & $<.0001$ \\
Marital status (ref: being & & & \\
$\quad$ unmarried) & & & \\
$\quad$ Married & 1.19 & $1.10-1.29$ & $<.0001$ \\
Living location before surgical & & & \\
$\quad$ hospitalization (ref: & & & \\
$\quad$ hospital) & & & \\
$\quad$ Overall & & & $<.0001$ \\
Home & 1.09 & $0.85-1.41$ & .50 \\
$\quad$ Extended care & 0.41 & $0.30-0.56$ & $<.0001$ \\
Level of amputation (ref: & & & \\
$\quad$ unilateral transtibial) & & & \\
$\quad$ Overall & & & $<.0001$ \\
$\quad$ Unilateral transfemoral & 0.88 & $0.79-0.96$ & .006 \\
$\quad$ Bilateral transtibial & 0.66 & $0.50-0.88$ & .005 \\
$\quad$ Bilateral transfemoral & 0.61 & $0.48-0.77$ & $<.0001$ \\
Elixhauser comorbidities & & & \\
Congestive heart failure & 0.86 & $0.78-0.94$ & .002 \\
Other neurologic disorders & 0.72 & $0.55-0.96$ & .02 \\
Psychoses & 0.75 & $0.64-0.88$ & .0003 \\
Valvular disease & 0.81 & $0.66-0.99$ & .04 \\
Weight loss & 0.82 & $0.68-0.99$ & .04 \\
Base & & &
\end{tabular}

Baseline complexity from surgical stay

Procedures

Acute central nervous system disorder

Ongoing active cardiac pathology

Serious nutritional compromise

Severe renal disease

Hospital characteristics of early rehabilitation

Regions (ref: Southeast)

Midwest

Mountain Pacific

Northeast

South Central

Rehabilitation (ref: specialized)

Consultative rehabilitation

No evidence of inpatient

rehabilitation

$0.81 \quad 0.69-0.95$

.009

$0.88 \quad 0.77-0.99$

.04

$\begin{array}{lll}0.68 & 0.51-0.89 \quad .005\end{array}$

$0.73 \quad 0.63-0.85<.0001$

Abbreviation: ref, reference.

significant. Table 4 shows the patient-, treatment-, and facilitylevel characteristics that remained independently associated with receipt of outpatient services after adjustment. With every 10 -year increase in age, the likelihood of receiving outpatient rehabilitation declined $(\mathrm{HR}=.83 ; 95 \% \mathrm{CI}, .80-.86)$. Veterans who were married were more likely to receive outpatient services $(\mathrm{HR}=1.19 ; 95 \% \mathrm{CI}, 1.10-1.29)$. Those patients who were admitted to the hospital from extended care compared with being transferred from another hospital were less likely to receive outpatient services $(\mathrm{HR}=.41 ; 95 \% \mathrm{CI}, .30-.56)$, whereas there was no difference for those admitted from home $(P=.50)$. Patients with transfemoral or bilateral amputations were less likely to initiate outpatient services than those with a single transtibial amputation $(P<.0001)$. Patients with comor- 
Table 5: Hazard Ratios at Different Time Points for Discharge Location That Violated the Assumption of Proportional Hazards

\begin{tabular}{|c|c|c|c|c|c|}
\hline & \multicolumn{5}{|c|}{ HR $(95 \% \mathrm{Cl})$} \\
\hline & Od & $90 \mathrm{~d}$ & $180 \mathrm{~d}$ & $270 d$ & $365 d$ \\
\hline \multicolumn{6}{|c|}{ Discharge location from hospital (ref: extended care) } \\
\hline Home & $3.6(3.2-4.1)$ & $1.3(1.2-1.5)$ & $0.5(0.4-0.6)$ & $0.2(0.1-0.3)$ & $.06(0-0.1)$ \\
\hline Other & $4.5(2.7-7.4)$ & $0.6(0.2-2.0)$ & $0.0(0-1.1)$ & $0.0(0-0.6)$ & $0.0(0-0.3)$ \\
\hline
\end{tabular}

Abbreviation: ref, reference.

bidities of congestive heart failure $(P=.002)$, neurologic disorders $(P=.02)$, psychoses $(P=.0003)$, valvular diseases $(P=.04)$, and weight loss $(P=.04)$ were all less likely to receive outpatient rehabilitation services. Patients with evidence of acute organ dysfunction associated with their surgical hospitalization as evidenced by procedures suggestive of acute central nervous system disorders $(P=.009)$, ongoing active cardiac pathology $(P=.04)$, serious nutritional compromise $(P=.005)$, and severe renal disease $(P<.0001)$ were less likely to obtain services. When compared with those who had specialized rehabilitation services, those who received consultation rehabilitation services during their index surgical stay were less likely to receive outpatient service $(P<.0001)$, and those with no evidence of rehabilitation during that period had no differences in the likelihood of receiving outpatient rehabilitation care.

Compared with the Southeast, those in the Midwest $(\mathrm{HR}=1.32 ; 95 \% \mathrm{CI}, 1.18-1.47)$ were more likely to receive outpatient rehabilitation services, while those in the Northeast $(\mathrm{HR}=.73 ; 95 \% \mathrm{CI}, .64-.83)$ were less likely.

There was only a single clinical characteristic that violated the proportional hazards assumption. Thus, the HRs for this variable did not remain constant over time (table 5). Compared with patients discharged to an extended care facility, the likelihood of receiving outpatient rehabilitation services for those discharged home or to a different location was much higher initially but then declined over time. By 180 days postdischarge, patients discharged home were less likely to initiate outpatient services, and those initially discharged to an extended care facility became more likely to receive outpatient services.

\section{DISCUSSION}

Identification of factors influencing receipt of outpatient rehabilitation services is important for gaining a better understanding of barriers to participation, and hence may enhance survival and quality of remaining life by improving mobility and function. ${ }^{1,5}$ In this observational study, we found that $65 \%$ of veterans with a lower extremity amputation received outpatient rehabilitation services. Similar observations have been found in patients with severe lower extremity trauma requiring amputation or reconstruction. ${ }^{7}$ However, most lower extremity amputations are performed as a result of dysvascular conditions, and most patients are elderly with many comorbidities ${ }^{20}$ and may have different functional needs from those with traumatic lower extremity amputation.

Our data demonstrate that veterans who were younger and underwent a unilateral transtibial amputation were more likely to receive outpatient rehabilitation. These patients usually had less severe comorbidities, might be considered "healthier," and may be perceived as being more likely to benefit from outpatient services. In contrast, veterans who were older, underwent higher level transfemoral or bilateral amputations, had more severe comorbidities, and who underwent procedures for complications during their surgical stay were less likely to receive outpatient rehabilitation services. There are several plausible explanations for their decreased participation. First, their functional goals may not be easily met in an outpatient setting, or prosthetic prescriptions may not be feasible. ${ }^{15}$ Second, medical complications and ongoing medical interventions may have interfered or made them less likely to tolerate rehabilitation therapies. Lastly, other barriers may exist, such as difficulty traveling to and from an outpatient rehabilitation program or lack of social supports to assist with getting to outpatient clinics.

Compared with discharge to extended care facilities, discharge to home or a different location is associated with an initial increased likelihood of receiving outpatient services, and then followed by a decreased likelihood by 180 days. It is likely that those discharged to home or to other locations begin their outpatient services earlier than those discharged to extended care facilities. The "late-onset" service pattern associated with extended care may reflect a lack of caregiver availability to be able to go home to begin with, resulting in the extended care stay in the first place. Patients receiving care in a VA extended care setting, such as a nursing home or domiciliary, may be discharged to the community at a later time, and then be considered eligible for outpatient rehabilitation after the majority of those discharged directly home have already begun those services.

Being married was associated with an increased likelihood of receiving outpatient rehabilitation, emphasizing the importance of psychosocial support in improving function after lower extremity amputation. Married people may be more able to cope with new illness or disability, ${ }^{21}$ may be more likely to be encouraged by a spouse to use rehabilitation services, and may be more likely to have someone to transport them to an outpatient clinic and help them negotiate the visit. Also, married people are more likely to be discharged home and thus may be more eligible for outpatient rehabilitation sooner.

Interestingly, veterans who received only inpatient consultation rehabilitation were less likely to receive outpatient rehabilitation services than those who received care in an SRU. The possible barriers may be associated with their greater illness burden, ${ }^{22}$ which can reduce the likelihood of prosthetic prescription. ${ }^{15}$

This study showed facility-level differences in the receipt of outpatient rehabilitation. Patients who received care in the Midwest were more likely to receive outpatient rehabilitation services. The reason for the regional difference is unclear, but may be related to differences in rehabilitation care patterns or service availability.

\section{Study Limitations}

This study includes only veterans, a predominantly older, male population; therefore, results may not be generalized to the general population or to women. Although our definition of outpatient rehabilitation services is broad, it is likely that some patients receive only home therapies or receive non-VA rehabilitation services, which the VA datasets would not capture. 
Vocational rehabilitation and mental health services were not included in this study, but have been considered to be common rehabilitation needs for patients with lower extremity trauma. ${ }^{23}$ Future research efforts are needed to identify what other types of services patients received.

\section{CONCLUSIONS}

Both clinical characteristics and types of inpatient rehabilitation received influence the receipt of outpatient rehabilitation services after lower extremity amputation in the veteran population. Geographic location also affected the receipt of outpatient rehabilitation, suggesting that care patterns are not standardized across the nation. Further understanding of these factors that result in variations may lead to improvements in the health care system.

\section{References}

1. Cutson TM, Bongiorni DR. Rehabilitation of the older lower limb amputee: a brief review. J Am Geriatr Soc 1996;44:1388-93.

2. Horgan O, MacLachlan M. Psychosocial adjustment to lower-limb amputation: a review. Disabil Rehabil 2004;26:837-50.

3. Pezzin LE, Dillingham TR, MacKenzie EJ. Rehabilitation and the long-term outcomes of persons with trauma-related amputations. Arch Phys Med Rehabil 2000;81:292-300.

4. Dillingham TR, Pezzin LE. Rehabilitation setting and associated mortality and medical stability among persons with amputations. Arch Phys Med Rehabil 2008;89:1038-45.

5. Stineman MG, Kwong PL, Kurichi JE, et al. The effectiveness of inpatient rehabilitation in the acute postoperative phase of care after transtibial or transfemoral amputation: study of an integrated health care delivery system. Arch Phys Med Rehabil 2008;89:1863-72.

6. Kurichi JE, Small DS, Bates BE, et al. Possible incremental benefits of specialized rehabilitation bed units among veterans after lower extremity amputation. Med Care 2009;47:457-65.

7. Castillo RC, MacKenzie EJ, Webb LX, Bosse MJ, Avery J. Use and perceived need of physical therapy following severe lowerextremity trauma. Arch Phys Med Rehabil 2005;86:1722-8.

8. Castillo RC, MacKenzie EJ, Archer KR, Bosse MJ, Webb LX. Evidence of beneficial effect of physical therapy after lowerextremity trauma. Arch Phys Med Rehabil 2008;89:1873-9.

9. VIReC research user guide. FY2000 VHA Medical SAS inpatient datasets. Edward J Hines, Jr, VA Hospital, Hines, IL: Veterans Affairs Information Resource Center; April 2003.

10. VIReC research user guide. FY2000 VHA Medical SAS outpatient datasets. Edward J Hines, Jr, VA Hospital, Hines, IL: Veterans Affairs Information Resource Center; January 2003.

11. Kubal JD, Webber S, Cooper DC, Waight S, Hynes DM. A primer on U.S. mortality databases used in health services research. Vol 5. Hines: VA Information Resource Center; 2000
12. VHA Office of Information. VHA corporate databases monograph. Available at: http://vaww4.va.gov/nds/CorporateDatabases Monograph/Monograph_2008.pdf. Accessed April 18, 2007.

13. Bates B, Stineman MG, Reker DM, Kurichi JE, Kwong PL. Risk factors associated with mortality in veteran population following transtibial or transfemoral amputation. J Rehabil Res Dev 2006; 43:917-28.

14. Bates BE, Kurichi JE, Marshall CR, Reker D, Maislin G, Stineman MG. Does the presence of a specialized rehabilitation unit in a Veterans Affairs facility impact referral for rehabilitative care after a lower-extremity amputation? Arch Phys Med Rehabil 2007;88:1249-55.

15. Kurichi JE, Kwong PL, Reker DM, Bates BE, Marshall CR, Stineman MG. Clinical factors associated with prescription of a prosthetic limb in elderly veterans. J Am Geriatr Soc 2007;55: 900-6.

16. Kurichi JE, Stineman MG, Kwong PL, Bates BE, Reker DM. Assessing and using comorbidity measures in elderly veterans with lower extremity amputations. Gerontology 2007;53: 255-9.

17. Mayfield JA, Reiber GE, Maynard C, Czerniecki JM, Caps MT, Sangeorzan BJ. Survival following lower-limb amputation in a veteran population. J Rehabil Res Dev 2001;38:341-5.

18. McWhinnie DL, Gordon AC, Collin J, Gray DW, Morrison JD Rehabilitation outcome 5 years after 100 lower-limb amputations. Br J Surg 1994;81:1596-9.

19. Elixhauser A, Steiner C, Harris DR, Coffey RM. Comorbidity measures for use with administrative data. Med Care 1998;36:8-27.

20. Rommers GM, Vos LD, Groothoff JW, Schuiling CH, Eisma WH. Epidemiology of lower limb amputees in the north of The Netherlands: aetiology, discharge destination and prosthetic use. Prosthet Orthot Int 1997;21:92-9.

21. Berg CA, Wiebe DJ, Butner J, et al. Collaborative coping and daily mood in couples dealing with prostate cancer. Psychol Aging 2008;23:505-16.

22. Bates BE, Kwong PL, Kurichi JE, et al. Factors influencing decisions to admit patients to veterans affairs specialized rehabilitation units after lower-extremity amputation. Arch Phys Med Rehabil 2009;90:2012-8.

23. Archer KR, Castillo RC, MacKenzie EJ, Bosse MJ. Perceived need and unmet need for vocational, mental health, and other support services after severe lower-extremity trauma. Arch Phys Med Rehabil 2010;91:774-80.

\section{Suppliers}

a. Agency for Healthcare Research and Quality, 540 Gaither Rd, Rockville, MD 20850.

b. SAS version 9.1; SAS Institute Inc, 100 SAS Campus Dr, Cary, NC 27513. 